\title{
KERAGAMAN GENETIK DAN HERITABILITAS KARAKTER KOMPONEN HASIL DAN HASIL CIPLUKAN (Physalis sp.)
}

\section{GENETIC VARIABILITY AND HERITABILITY CHARACTERS OF YIELD COMPONENT AND YIELD OF PHYSALIS (Physalis sp.)}

\author{
Effendy $^{1}$, Respatijarti ${ }^{2}$, Budi Waluyo ${ }^{2}$ \\ ${ }^{1}$ Program Studi Agroekoteknologi, Fakultas Pertanian, Universitas Brawijaya \\ 2 Jurusan Budidaya Pertanian, Fakultas Pertanian, Universitas Brawijaya \\ Jalan Veteran, Malang 65145, Jawa Timur, Indonesia \\ Korespondensi : budiwaluyo@ub.ac.id
}

Diterima 14 Desember 2017 / Disetujui 21 Juni 2018

\begin{abstract}
ABSTRAK
Ciplukan (Physalis sp.) merupakan salah satu tumbuhan yang potensial untuk dikembangkan sebagai sumber biofarmaka dan buah di Indonesia. Peningkatan produksi ini dapat dilakukan melalui penyediaan varietas-varietas unggul ciplukan dengan meningkatkan kapasitas genetik melalui program pemuliaan tanaman. Pemuliaan tanaman akan berhasil jika terdapat keragaman genetik yang luas dan heritabilitas tinggi. Penelitian ini bertujuan untuk mempelajari keragaman genetik dan heritabilitas pada karakter komponen hasil dan hasil ciplukan. Percobaan menggunakan rancangan acak kelompok dengan 34 aksesi ciplukan sebagai perlakuan diulang tiga kali. Penelitian dilaksanakan di Kelurahan Areng-Areng, Kecamatan Junrejo, Kota Batu pada bulan Mei - September 2017. Karakter pada tanaman ciplukan ada yang mempunyai keragaman luas dan ada yang mempunyai keragaman sempit. Keragaman yang luas terdapat pada tinggi batang, jumlah bunga per tanaman, bobot per buah tanpa kelopak, bobot per buah dengan kelopak, jumlah buah per tanaman, jumlah buah segar per tanaman, bobot buah per tanaman dan bobot buah segar per tanaman. Keragaman yang sempit terdapat pada karakter diameter batang, jumlah cabang tersier, jumlah bunga per cabang tersier, panjang tangkai buah, panjang kelopak, diameter kelopak, panjang buah, diameter buah, dan kemanisan buah. Nilai heritabilitas pada semua karakter termasuk kriteria tinggi. Hal ini menunjukkan pengaruh genetik lebih besar dibandingkan dengan faktor fenotip pada penampilan karakter tanaman ciplukan.
\end{abstract}

Kata kunci : Ciplukan, Heritabilitas, Keragaman genetik.

\begin{abstract}
Ciplukan (Physalis sp.) is one of the potential plant to be developed as a source of medical plant and fruit in Indonesia. Increase production of this plant can be done through the provision of improved varieties of ciplukan by increasing the genetic capacity through plant breeding programs. Plant breeding will be successful if there is high genetic variability and heritability. This study aimed to study genetic variability and heritability on the character of yield component and yield in Physalis. The experiment used a randomized block design with 34
\end{abstract}

Cyte this as: Effendy, Respatijarti, \& Waluyo, B. (2018). Keragaman genetik dan heritabilitas karakter komponen hasil dan hasil ciplukan (Physalis sp.). Jurnal Agro, 5(1), 30-38. https://doi.org/10.15575/1864 
accessions of ciplukan as treatment repeated three times. The research was conducted in Areng-Areng sub-district, Junrejo District, Batu City from May until September 2017. Characters in ciplukan plants have wide and narrow variability. Characters that have a wide variability are stem height, number of flower per plant, number of fruits per plant, number of fruits per plant, weight per fruit without husks, weight per fruit with husk, weight of fruit per plant, and weight of fresh fruit per plant. Characters that have narrow variability are stem diameter, number of tertiary branching, number of flower per tertiary branching, length of fruit stalk, husk length, husk diameter, fruit length, fruit diameter, and sweetness. All characters have high heritability. This shows a greater genetic influence compared to phenotypic factors on the appearance of ciplukan characters.

Key words : Physalis, genetic variablity, heritability,

\section{PENDAHULUAN}

Physalis sp. merupakan tanaman yang potensial untuk dikembangkan di Indonesia. Hal ini karena tanaman ini menyebar di seluruh wilayah Indonesia dengan nama daerah yang beragam. Ada kemungkinan tumbuhan ini berasal dari wilayah Indonesia karena variasi yang terjadi bisa diakibatkan oleh lingkungan tempat tumbuh pada ketinggian berbeda, dan juga lokasi yang terpisah antar pulau yang bisa menjadi isolasi alami terjadinya keragaman genetik (Richards et al., 2007). Physalis dipulau Jawa dikenal dengan nama cecendet (Sunda) atau ciplukan (Jawa). Physalis merupakan tumbuhan liar yang biasanya dijadikan sumber makanan bagi binatang liar (Farida, 2015; Dapsia et al., 2017; Jasmi, 2017) atau gulma yang secara terus menerus dikendalikan dan dimusnahkan (Travlos, 2012; Price et al., 2013). Jika pengendalian gulma ini terus dilakukan maka tumbuhan ini terancam punah (Intzaar et al., 2013).

Physalis telah dimanfaatkan sebagai sumber buah atau obat tradisional sehingga dapat dikembangkan sebagai bahan baku bidang biofarmaka ataupun non biofarmaka. Manfaat di bidang biofarmaka digunakan sebagai obat-obatan seperti obat anti kanker, anti diare, obat bisul, dan obat lainnya karena kandungan yang terdapat pada ciplukan seperti fisalin B, D, F (Sharma et al., 2015). Selain itu juga sebagai bahan baku seperti pembuatan jeli, selai, jus dan es krim (Muniz et al., 2014). Tanaman ciplukan di Indonesia merupakan tumbuhan liar serta dianggap sebagai gulma, sehingga setiap saat selalu dikendalikan dengan cara dimatikan. Hal ini akan menyebabkan ciplukan di Indonesia akan mengalami kepunahan jika tidak dilakukan pengelolaan konservasi sumberdaya genetik tanaman ciplukan. Dilihat dari potensi yang ada pada tanaman ciplukan maka perlu dilakukan pengembangan pada tanaman ini melalui peningkatan kapasitas genetik melalui program pemuliaan tanaman.

Keragaman genetik dan heritabilitas merupakan syarat mutlak dalam keberhasilan suatu program pemuliaan tanaman (Acquaah, 2012). Keragaman genetik dapat memperbesar kemungkinan untuk mendapatkan genotip yang lebih baik melalui seleksi. Keragaman karakter dan keanekaragaman genotip berguna untuk mengetahui pola pengelompokan genotip pada populasi tertentu berdasarkan karakter yang diamati dan dapat dijadikan sebagai dasar kegiatan 
seleksi (Agustina \& Waluyo, 2017). Analisis keragaman dapat dilakukan dengan berbagai tipe penanda, salah satu tipe penandanya ialah morfologi pada tanaman tersebut (Nadhifah et al., 2016). Indikator bahwa karakter tersebut dikendalikan secara genetik berdasarkan nilai heritabilitas.

Heritabilitas merupakan parameter genetik yang digunakan untuk mengukur kemampuan genotip dalam populasi tanaman dalam mewariskan karakter yang dimilikinya (Meena et al., 2016). Nilai duga heritabilitas memiliki fungsi diantaranya untuk menentukan keberhasilan seleksi, karena dapat memberikan petunjuk suatu sifat lebih dipengaruhi oleh faktor genetik atau faktor lingkungan (Rosmaina et al., 2016).

Penelitian ini bertujuan untuk mengetahui keragaman genetik dan heritabilitas pada karakter komponen hasil dan hasil ciplukan.

\section{BAHAN DAN METODE}

Penelitian dilaksanakan pada bulan Mei - September 2017. Lokasi penelitian berada di Kelurahan Areng-Areng, Kecamatan Junrejo, Kota Batu, dengan ketinggian tempat $635 \mathrm{~m}$ dpl. Bahan yang digunakan adalah 34 aksesi ciplukan yang terdiri dari Physalis angulata dan Physalis peruviana, media semai cocopeat dan kompos dengan perbandingan 2:1, pupuk kandang $150 \mathrm{~kg}$ $\mathrm{ha}^{-1}$, pupuk Urea $120 \mathrm{~kg} \mathrm{ha}^{-1}$, pupuk SP-36 $300 \mathrm{~kg} \mathrm{ha}{ }^{-1}$, pupuk $\mathrm{KCl} 200 \mathrm{~kg} \mathrm{ha}{ }^{-1}$, fungisida dengan bahan aktif metalaksil $35 \%$, insektisida dengan bahan aktif 25\%, mulsa plastik hitam perak. Alat yang digunakan dalam penelitian ini adalah tray persemaian, kain peram, gembor, cangkul, ajir bambu, tali, papan penanda, refraktometer, timbangan analitik, jangka sorong, penggaris, alat tulis dan kamera.

Penelitian menggunakan metode eksperimen disusun berdasarkan Rancangan Acak Kelompok (RAK) dengan perlakuan 34 aksesi ciplukan yang diulang sebanyak tiga kali sehingga diperoleh 102 satuan percobaan. Dalam setiap percobaan terdapat 5 tanaman.

Pengamatan dilakukan pada karakter kuantitatif yaitu: tinggi batang $(\mathrm{cm})$, diameter batang $(\mathrm{mm})$, jumlah cabang tersier (cabang), jumlah bunga per cabang tersier (bunga), jumlah bunga per tanaman (bunga), jumlah buah per tanaman (buah), jumlah buah segar per tanaman (buah), panjang tangkai buah $(\mathrm{cm})$, panjang kelopak $(\mathrm{cm})$, diameter kelopak $(\mathrm{mm})$, panjang buah $(\mathrm{cm})$, diameter buah $(\mathrm{mm})$, bobot per buah dengan kelopak (g), bobot per buah tanpa kelopak (g), bobot buah per tanaman dengan kelopak (g), bobot buah segar per tanaman (g), dan level kemanisan (Brix\%). Prosedur pengamatan mengacu pada Descriptor for Physalis (UPOV, 2007).

Tabel 1. Kuadrat tengah harapan berdasarkan rancangan acak kelompok.

\begin{tabular}{cccc}
\hline $\begin{array}{c}\text { Sumber } \\
\text { ragam }\end{array}$ & $\mathrm{Db}$ & $\mathrm{KT}$ & $\mathrm{KTH}$ \\
\hline $\begin{array}{c}\text { Ulangan } \\
\text { Aksesi }\end{array}$ & $\mathrm{r}-1$ KT-1 & KTA & $\sigma^{2}{ }_{\mathrm{e}}+\mathrm{r}^{2}{ }_{\mathrm{g}}$ \\
Galat & $(\mathrm{r}-1)(\mathrm{a}-1)$ & $\mathrm{KTE}$ & $\sigma_{\mathrm{e}}^{2}$ \\
\hline Total & ra-1 & \\
\hline Keterangan: & & \\
$\sigma_{\mathrm{e}}^{2}$ & $=$ KT galat \\
$\sigma_{\mathrm{g}}^{2}$ & $=\frac{\text { KT genotip-KT galat }}{{ }^{\mathrm{r}}}$ \\
$\sigma_{\mathrm{f}}^{2}$ & $=\sigma_{\mathrm{g}}^{2}+\sigma_{\mathrm{e}}^{2}$
\end{tabular}

Data karakter kuantitatif dianalisis menggunakan analisi ragam (ANOVA) (Tabel 1). Selanjutnya dilakukan 
perhitungan Koefisien Variasi Fenotip (KVF) dan Koefisien Variasi Genetik (KVG), serta mengitung nilai heritabilitas.

Menurut (Kearsey \& Pooni, 1996), Koefisien Variasi Fenotip (KVF) dan Koefisien Variasi Genetik (KVG) tiap karakter dihitung dengan rumus:

$$
\begin{aligned}
& \mathrm{KVF}=\frac{\sqrt{\sigma_{\mathrm{f}}^{2}}}{\bar{X}} \times 100 \% \\
& \mathrm{KVG}=\frac{\sqrt{\sigma_{\mathrm{g}}^{2}}}{\overline{\mathrm{X}}} \times 100 \%
\end{aligned}
$$

Keterangan:

$$
\begin{array}{ll}
\sigma_{\mathrm{g}}^{2} & =\text { Varians genetik } \\
\sigma_{f}^{2} & =\text { Varians fenotip } \\
\overline{\mathrm{X}} & =\text { rata-rata tiap karakter } \\
& \text { tanaman }
\end{array}
$$

Kriteria keluasan keragaman ditentukan berdasarkan pada nilai koefiesien variasi dengan rentang $0-100 \%$ kuartil, yaitu rendah $(0 \% \leq 25 \%)$, agak rendah $(25 \% \leq$ $50 \%)$, cukup tinggi $(50 \% \leq 75 \%)$, dan tinggi $(75 \% \leq 100 \%)$. Nilai ini direntang ulang dengan menggunakan nilai koefisien variasi tertinggi dari seluruh karakter yang diamati sebagai nilai $100 \%$.

Heritabilitas dalam arti luas $\left(\mathrm{h}^{2}\right)$ dihitung berdasarkan pemisahan komponen varians dengan rumus (Acquaah, 2012):

$$
\mathrm{h}^{2}=\frac{\sigma_{g}^{2}}{\sigma_{g}^{2}+\sigma_{e}^{2}}
$$

Keterangan:

$$
\begin{array}{ll}
\sigma_{g}^{2} & =\text { Varians genetik } \\
\sigma_{e}^{2} & =\text { Varians lingkungan }
\end{array}
$$

Kriteria nilai duga heritabilitas dalam arti luas adalah tinggi $\left(\mathrm{h}^{2}>0,50\right)$, sedang $\left(0,20 \leq h^{2} \leq 0,50\right)$, rendah $\left(h^{2}<0,20\right)$ (Stansfield, 1991).

\section{HASIL DAN PEMBAHASAN}

\section{Keragaman Genetik}

Berdasarkan analisis varians diperoleh nilai komponen varians genetik dan varians fenotip yang digunakan untuk menghitung Koefisien Variasi Genetik (KVG) dan Koefisien Variasi Fenotip (KVF). Karakter pada tanaman ciplukan yang diteliti mempunyai nilai koefisien variasi genetik tertinggi $85,17 \%$ dan dinyatakan sebagai $100 \%$, serta nilai koefisien fenotip tertinggi karakter $88,11 \%$ sebagai $100 \%$. Dengan demikian kriteria keluasan keragaman berdasarkan KVG ialah 0\% - 21,3\% rendah, $21,3 \%-42,6 \%$ agak rendah, $42,6 \%-63,9 \%$ cukup tinggi dan $>63,9 \%$ tinggi. Indikator keragaman fenotip berdasarkan KVF ialah $0 \%-22 \%$ rendah, $22 \%$ - $44 \%$ agak rendah, $44 \%-66 \%$ cukup tinggi dan $>66 \%$ tinggi. Pada karakter dengan nilai koefisien varians rendah dan agak rendah digolongkan sebagai karakter dengan keragaman sempit, sedangkan karakter dengan nilai koefisien varians genetik agak tinggi dan tinggi digolongkan sebagai karakter dengan keragaman luas. Hasil penelitian menunjukkan karakter pada 34 aksesi ciplukan memiliki keragaman yang sempit sampai keragaman luas (Tabel 2).

Karakter dengan keragaman genetik sempit terdapat pada karakter diameter batang, jumlah cabang tersier, jumlah bunga per cabang tersier, panjang tangkai buah, panjang kelopak, diameter kelopak, panjang buah, diameter buah, dan level kemanisan. Sempitnya keragaman genetik karena karakter pada genotip yang digunakan tidak memiliki variasi sifat yang lebar pada karakter tersebut. Dengan demikian jika dilakukan seleksi pada karakter-karakter tersebut maka akan 
Tabel 2. Nilai Koefisien Variasi Genetik (KVG), Koefisien Variasi Fenotip (KVF) pada karakter komponen hasil dan hasil ciplukan

\begin{tabular}{|c|c|c|c|c|c|}
\hline Karakter Pengamatan & $\begin{array}{l}\text { Rata- } \\
\text { rata }\end{array}$ & KVG (\%) & Kriteria & KVF (\%) & Kriteria \\
\hline Tinggi batang $(\mathrm{cm})$ & 18,91 & 73,82 & Cukup tinggi & 74,93 & Cukup tinggi \\
\hline Diameter batang (mm) & 10,30 & 24,94 & Rendah & 32,01 & Agak rendah \\
\hline $\begin{array}{l}\text { Jumlah cabang tersier } \\
\text { (cabang) }\end{array}$ & 29,82 & 30,99 & Agak rendah & 32,52 & Agak rendah \\
\hline $\begin{array}{l}\text { Jumlah bunga per cabang } \\
\text { tersier (bunga) }\end{array}$ & 3,25 & 22,93 & Rendah & 30,13 & Agak rendah \\
\hline $\begin{array}{l}\text { Jumlah bunga per tanaman } \\
\text { (bunga) }\end{array}$ & 107,36 & 58,98 & Cukup tinggi & 65,38 & Cukup tinggi \\
\hline $\begin{array}{l}\text { Jumlah buah per tanaman } \\
\text { (buah) }\end{array}$ & 82,40 & 76,55 & Tinggi & 79,65 & Tinggi \\
\hline $\begin{array}{l}\text { Jumlah buah segar per } \\
\text { tanaman (buah) }\end{array}$ & 74,58 & 80,16 & Tinggi & 84,54 & Tinggi \\
\hline Panjang tangkai buah $(\mathrm{cm})$ & 1,94 & 13,59 & Rendah & 16,20 & Rendah \\
\hline Panjang kelopak $(\mathrm{cm})$ & 2,56 & 20,16 & Rendah & 21,77 & Rendah \\
\hline Diameter kelopak (mm) & 19,11 & 25,58 & Agak rendah & 26,23 & Agak rendah \\
\hline Panjang buah $(\mathrm{cm})$ & 1,82 & 18,89 & Rendah & 20,46 & Rendah \\
\hline Diameter buah $(\mathrm{mm})$ & 16,51 & 23,95 & Rendah & 25,19 & Agak rendah \\
\hline $\begin{array}{l}\text { Bobot per buah tanpa } \\
\text { kelopak }(\mathrm{g})\end{array}$ & 2,86 & 74,67 & Cukup tinggi & 74,84 & Cukup tinggi \\
\hline $\begin{array}{l}\text { Bobot per buah dengan } \\
\text { kelopak }(\mathrm{g})\end{array}$ & 3,06 & 71,30 & Cukup tinggi & 71,48 & Cukup tinggi \\
\hline Bobot buah per tanaman (g) & 172,71 & 81,72 & Tinggi & 84,29 & Tinggi \\
\hline $\begin{array}{l}\text { Bobot buah segar per } \\
\text { tanaman }(\mathrm{g})\end{array}$ & 150,51 & 85,17 & Tinggi & 88,11 & Tinggi \\
\hline Level kemanisan (Brix\%) & 12,56 & 10,05 & Rendah & 10,64 & Rendah \\
\hline
\end{tabular}

Keterangan: KVG: koefisien variasi genetik, KVF: koefisien variasi fenotip. Kriterian KVG: rendah (0\% $21,3 \%)$, agak rendah $(21,3 \%-42,6 \%)$, cukup tinggi $(42,6 \%-63,9 \%)$, dan tinggi $(>63,9 \%)$. Kriteria KVF: rendah (0\% - 22\%), agak rendah (22\% - 44\%), cukup tinggi (44\% - 66\%), dan tinggi (>66\%).

Karakter dengan keragaman genetik luas terdapat pada tinggi batang, jumlah bunga per tanaman, jumlah buah per tanaman, jumlah buah segar per tanaman, bobot per buah tanpa kelopak, bobot per buah dengan kelopak, bobot buah per tanaman, dan bobot buah segar per tanaman. Keragaman genetik yang luas ini karena setiap karakter mempunyai sifat yang bervariasi. Variasi pada sifat pada karakter diduga disebabkan oleh asal usul dari bahan tanam yang diuji yaitu Jawa
Timur, Jawa Tengah, Jawa Barat, Thailand, dan Belanda. Keragaman genetik suatu tanaman dapat disebabkan karena sebagian besar aksesi yang diuji adalah tipe populasi lokal yang berasal dari latar belakang genetik yang berbeda, misalnya: lokasi pengambilan bahan tanaman yang diambil berasal dari wilayah administratif berbeda (Sood \& Kumar, 2011; Hirota et al., 2012).

Keragaman genetik luas menandakan keefektifan seleksi atau keberhasilan suatu 
kegiatan pemuliaan tanaman (Jalata et al., 2011). Semakin luas keragaman suatu karakter pada populasi maka semakin bervariasi sifat yang ada pada karakter yang mencerminkan pengendalian genetik pada populasi. Pengendalian genetik yang tinggi pada karakter maka peluang untuk mendapatkan genotip dengan sifat karakter yang lebih baik melalui seleksi semakin besar.

\section{Heritabilitas}

Heritabitas merupakan parameter genetik sebagai dasar dari sifat suatu karakter pada tetua diwariskan kepada keturunan selanjutnya. Heritabilitas merupakan proporsi dari ragam genetik terhadap ragam fenotip. Nilai heritabilitas diperlukan bahwa suatu karakter dipengaruhi oleh faktor genetik atau faktor lingkungan. Nilai heritabilitas berkisar antara 0 sampai 1 . Nilai heritabilitas semakin mendekati 1 dinyatakan heritabilitasnya semakin tinggi dan dipengaruhi oleh faktor genetik, sebaliknya nilai heritabilitas semakin mendekti 0 heritabilitasnya semakin rendah yang artinya penampilan karakter dipengaruhi oleh faktor lingkungan.

Pada hasil analisis dari semua karakter komponen hasil dan hasil pada tanaman ciplukan didapatkan nilai heritabilitas berkisar antara 0,58 sampai dengan 0,99 atau termasuk dalam kriteria tinggi, yang artinya bahwa karakter dengan kriteria tinggi menunjukkan bahwa karakter tersebut lebih dipengaruhi oleh faktor genetik daripada faktor lingkungan (Tabel 3). Karakter pada tanaman ciplukan yang memiliki heritabilitas yang tinggi dengan nilai berkisar antara 0,48 sampai 1 yang terdapat pada karakter hasil, berat buah, bentuk buah (diameter) dan kemanisan buah (Leiva-Brondo et al., 2001). Lomeli et al. (2008) juga mendapatkan nilai heritabilitas berkisar antara 0,52 sampai 0,59 yang termasuk dalam kriteria heritabilitas tinggi, karakter pada tanaman ciplukan yang memiliki nilai duga heritabilitas yang tinggi terdapat pada karakter tinggi cabang pada batang utama, buah pertanaman pada panen pertama, jumlah buah pertanaman. Karakter dengan nilai heritabilitas tinggi pada kerabat ciplukan dengan kisaran nilai 0,68 sampai dengan 0,84 terdapat pada karakter tinggi batang, jumlah buah pertanaman, dan bobot perbuah (Islam et al., 2013).

Tingginya nilai heritabilitas dapat disebabkan oleh metode evaluasi genetik. Jika evaluasi berdasarkan pada individu tanaman maka nilai heritabilitas relatif lebih rendah. Sebaliknya nilai heritabilitas relatif tinggi apabila dievaluasi didasarkan pada populasi tanaman. Pada peningkatan kapasitas genetik melalui pemuliaan tanaman, sifat-sifat tertentu seperti hasil panen biasanya diukur berdasarkan plot bukan pada tanaman individu (Acquaah, 2012).

Umumnya suatu karakter tanaman yang mempunyai nilai KVG tinggi belum tentu mempunyai nilai heritabilitas tinggi, dan sebaliknya. Pada penelitian ini didapatkan bahwa ada karakter yang mempunyai nilai KVG tinggi dan heritabilitas tinggi, KVG rendah dan heritabilitas tinggi. Dengan demikian nilai KVG dan heritabilitas tidak selalu linier sama besar. Hal ini, karena ada faktor lingkungan yang mempengaruhi nilai heritabilitas. Suatu karakter tanaman yang memiliki keragaman genetik yang rendah serta nilai heritabilitas yang tinggi menunjukkan bahwa secara populasi karakter tersebut seragam dan penampilan karakter tersebut sangat dipengaruhi oleh 
oleh faktor genetik. Nilai KVG tinggi serta nilai heritabilitas yang rendah menunjukkan bahwa karakter tersebut mempunyai variasi yang besar, tetapi variasi karakter pada genotip-genotip lebih besar dipengaruhi oleh lingkungan. Jika nilai KVG dan heritabilitas yang tinggi pada suatu karakter menujukkan bahwa karakter tersebut mempunyai pengaruh faktor genetik yang besar sehingga penampakan fenotipnya karakter akan lebih terekspresi sebagai pengaruh genetik dan sedikit dipengaruhi oleh lingkungan (Islam et al., 2013).

Tabel 3. Nilai heritabilitas pada karakter komponen hasil dan hasil ciplukan.

\begin{tabular}{lrrrrc}
\hline \multicolumn{1}{c}{ Karakter Pengamatan } & \multicolumn{1}{c}{$\sigma_{\mathrm{e}}{ }^{2}$} & \multicolumn{1}{c}{$\sigma_{\mathrm{g}}{ }^{2}$} & \multicolumn{1}{c}{$\sigma_{\mathrm{f}}{ }^{2}$} & \multicolumn{1}{c}{$\mathbf{H}$} & Kriteria H \\
\hline Tinggi batang (cm) & 5,89 & 194,96 & 200,85 & 0,97 & Tinggi \\
Diameter batang (mm) & 4,27 & 6,59 & 10,86 & 0,61 & Tinggi \\
Jumlah cabang tersier (cabang) & 8,65 & 85,42 & 94,07 & 0,91 & Tinggi \\
Jumlah bunga per cabang tersier & 0,40 & 0,55 & 0,96 & 0,58 & Tinggi \\
(bunga) & & & & & \\
Jumlah bunga per tanaman (bunga) & 916,92 & $4.009,98$ & $4.926,91$ & 0,81 & Tinggi \\
Jumlah buah per tanaman (buah) & 328,98 & $3.979,18$ & $4.308,16$ & 0,92 & Tinggi \\
Jumlah buah segar per tanaman & 401,42 & $3.574,32$ & $3.975,74$ & 0,90 & Tinggi \\
(buah) & & & & & \\
Panjang tangkai buah (cm) & 0,03 & 0,07 & 0,10 & 0,70 & Tinggi \\
Panjang kelopak (cm) & 0,04 & 0,27 & 0,31 & 0,86 & Tinggi \\
Diameter kelopak (mm) & 1,24 & 23,88 & 25,11 & 0,95 & Tinggi \\
Panjang buah (cm) & 0,02 & 0,12 & 0,14 & 0,85 & Tinggi \\
Diameter buah (mm) & 1,66 & 15,62 & 17,28 & 0,90 & Tinggi \\
Bobot per buah tanpa kelopak $(\mathrm{g})$ & 0,02 & 4,36 & 4,38 & 0,99 & Tinggi \\
Bobot per buah dengan kelopak $(\mathrm{g})$ & 0,02 & 4,56 & 4,58 & 0,99 & Tinggi \\
Bobot buah per tanaman $(\mathrm{g})$ & $1.273,50$ & $19.919,98$ & $21.193,48$ & 0,94 & Tinggi \\
Bobot buah segar per tanaman $(\mathrm{g})$ & $1.153,36$ & $16.433,68$ & $17.587,04$ & 0,93 & Tinggi \\
Level kemanisan (Brix\%) & 0,19 & 1,60 & 1,79 & 0,89 & Tinggi \\
\hline Keterangan: $\sigma_{\mathrm{e}}{ }^{2}:$ ragam lingkungan, $\sigma_{\mathrm{g}}{ }^{2}:$ ragam genetik, $\sigma_{\mathrm{f}}^{2}:$ ragam fenotip, $\mathrm{h}^{2}:$ heritabilitas. Kriteria \\
$\quad$ heritabilitas: tinggi $\left(\mathrm{h}^{2}>0,5\right)$, sedang $\left(0,2 \leq \mathrm{h}^{2}<0,5\right)$, rendah $\left(\mathrm{h}^{2}<0,2\right)$. &
\end{tabular}

\section{SIMPULAN}

1. Karakter ciplukan yang mempunyai keragaman luas terdapat pada tinggi batang, jumlah bunga per tanaman, bobot per buah tanpa kelopak, bobot per buah dengan kelopak, jumlah buah per tanaman, jumlah buah segar per tanaman, bobot buah per tanaman dan bobot buah segar per tanaman. Karakter yang mempunyai keragaman sempit terdapat pada diameter batang, jumlah bunga per cabang tersier, panjang tangkai buah, panjang kelopak, panjang buah diameter buah, jumlah cabang tersier, diameter kelopak, dan level kemanisan.

2. Semua karakter ciplukan yang diamati mempunyai heritabilitas tinggi

\section{DAFTAR PUSTAKA}

Acquaah, G. (2012). Principles of Plant Genetics and Breeding (2nd ed.). Oxford, UK: Wiley-Blackwell A John Wiley \& Sons, Ltd., Publication.

Agustina, N. I., \& Waluyo, B. (2017). Keragaman karakter morfo-agronomi 
dan keanekaragaman galur- galur cabai besar (Capsicum annuum L.). Jurnal Agro, 4(2), 120-130. https://doi.org/10.15575/1608

Bell, V., \& Oliver, L. (1979). Germination, control, and competition of cutleaf groundcherry (Physalis angulata) in soybeans. Weed Science, 27(1), 133138.

https://doi.org/10.1017/s004317450 0043654

Dapsia Djakbé, J., Ngakou, A., Christian, W., Faïbawe, E., \& Fohouo Tchuenguem, N.-F. (2017). Pollination and yield components of Physalis minima (Solanaceae) as affected by the foraging activity of Apis mellifera (Hymenoptera: Apidae) and compost at Dang (Ngaoundéré, Cameroon). Int. J. Agron. Agri. R. International Journal of Agronomy and Agricultural Research, 11(3), 43-60. Retrieved from http://www.innspub.net/wpcontent/uploads/2017/10/IJAARV11No3-p43-60.pdf.

Farida, W. R. (2015). Diversitas tumbuhan pakan, habitat dan pemanfaatan landak (Hystrix sp.) di Sumatera Selatan dan Kalimantan Timur [Diversity of feed plant, habitat, and use of porcupine (Hystrix sp.) in South Sumatra and East Kalimantan]. In Prosiding Seminar Nasional Masyarakat Biodiversitas Indonesia (Vol. 1, pp. 673-681). https://doi.org/10.13057/psnmbi/m0 10348

Hirota, T., Sayama, T., Yamasaki, M., Sasama, H., Sugimoto, T., Ishimoto, M., \& Yoshida, S. (2012). Diversity and population structure of black soybean landraces originating from Tanba and neighboring regions. Breeding Science, 61(5), 593-601. https://doi.org/10.1270/jsbbs.61.593

Intzaar, S., Akram, M., \& Afrasiab, H. (2013). High frequency multiple shoot formation of pygmy groundcherry (Physalis minima): an endangered medicinal plant. International Journal of Agriculture \& Biology, 15(4), 755760. Retrieved from http://www.fspublishers.org

Islam, M., Mohanta, H., Ismail, M., Rafii, M., \& Malek, M. (2013). Genetic variability and trait relationship in cherry tomato (Solanum lycopersicum L. var. cerasiforme (Dunnal) A. Gray). Bangladesh Journal of Botany, 41(2), 163-167.

https://doi.org/10.3329/bjb.v41i2.13 443

Jalata, Z., Ayana, A., \& Zeleke, H. (2011). Variability, heritability and genetic advance for some yield and yield related traits in Ethiopian barley (Hordeum vulgare L.) landraces and crosses. International Journal of Plant Breeding and Genetics, 5(1), 44-52. https://doi.org/10.3923/ijpbg.2011.4 4.52

Jasmi. (2017). Diversity and blooming season of food sources plant of Apis cerana (Hymenoptera: Apidae) in polyculture plantation in West Sumatra, Indonesia JASMI. Biodiversitas, 18(1), 34-40. https://doi.org/10.13057/biodiv/d180 106

Kearsey, M. J. J., \& Pooni, H. S. S. (1996). The Genetical Analysis of Quantitative Traits. London: Chapman \& Hall.

Leiva-Brondo, M., Prohens Tomás, J., \& Nuez Viñals, F. (2001). Genetic analysis indicate superiority of perfomance of cape gooseberry (Physalis peruviana L.) hybrids. Journal of New Seeds, 3(3), 71-84. https://doi.org/10.1300/J153v03n03

Lomelí A. Peña, J. D. Molina-Galán, J. Sahagún-Castellanos, J. OrtizCereceres, F. Márquez-Sánchez, T. C. y J. F. S. (2008). Genetic parameters of the husk tomato ( Physalis ixocarpa 
Brot.) CHF1 cultivar. Rev. Chapingo Ser.Hortic, 14(1).

Meena, M. ., Kumar, N., Meena, J. K., \& Rai, T. (2016). Genetic variability, heritability and genetic advance in chilli, Capsicum annuum. Bioscience Biotechnology Reaserch Communications, 9(2), 258-262. Retrieved from http//www.bbrc.in/

Muniz, J., Kretzschmar, A. A., Rufato, L., Pelizza, T. R., Rufato, A. D. R., \& Macedo, T. A. de. (2014). General aspects of Physalis cultivation. Ciência Rural, 44(6), 964-970. https://doi.org/10.1590/S010384782014005000006

Nadhifah, A., Suratman, \& Pitoyo, A. (2016). Kekerabatan fenetik ciplukan (Physalis angulata L.) di wilayah eksKaresidenan Surakarta berdasarkan karakter morfologis, palinologis dan pola pita isozim [Phenetic relationship among ciplukan (Physalis angulata L.) in Surakarta based on variation. Jurnal Tumbuhan Obat Indonesia, 9(1), 1-10. DOI: 10.22435/toi.v9i1.6336.1-10

Price, A. J., Monks, C. D., \& Kelton, J. A. (2013). Cutleaf groundcherry (Physalis angulata) density, biomass and seed production in peanut (Arachis hypogaea L.) following regrowth due to inadequate control. International Journal of Pharma and Bio Sciences, 4(3), 120-126. https://doi.org/10.3146/PS12-8.1.

Richards, C. L., Carstens, B. C., \& Lacey Knowles, L. (2007). Distribution modelling and statistical phylogeography: an integrative framework for generating and testing alternative biogeographical hypotheses. J. Biogeogr., 34(11), 1833-1845.

https://doi.org/10.1111/j.1365-

2699.2007.01814.x
Rosmaina, Syafrudin, Hasrol, Yanti, F., Juliyanti, \& Zulfahmi. (2016). Estimation of variability, heritability and genetic advance among local chili pepper genotypes cultivated in peat lands. Bulgarian Journal of Agricultural Science, 22(3), 431-436.

Sharma, N., Bano, A., Dhaliwal, H. S., \& Sharma, V. (2015). A pharmacological comprehensive review on "Rassbhary" Physalis angulata (L.). International Journal of Pharmacy and Pharmaceutical Sciences, 7(8), 34-38.

Sood, S., \& Kumar, N. (2011). Morphological studies of bell pepper germplasm. International Journal of Vegetable Science, 17(2), 144-156. https://doi.org/10.1080/19315260.20 10.519373

Stansfield, W. D. (1991). Theory and Problems of Genetics (Schaum's Outline Series). Toronto: McGraw-Hill Inc.

Travlos, I. S. (2012). Invasiveness of cut-leaf ground-cherry (Physalis angulata L.) populations and impact of soil water and nutrient availability. Chilean Journal of Agricultural Research, 72(3), 358-363. https://doi.org/10.4067/S071858392012000300009

UPOV. (2007). International union for the protection of new varieties of plants (pp. 1-29).

Zafar, N., Aziz, S., \& Masood, S. (2004). Phenotypic divergence for agromorphological traits among landrace genotypes of rice (Oryza sativa L.) from Pakistan. International Journal of Agriculture and Biology, 6(2), 335339. 